as should be the case if they were to arise de novo. Again, they appear only after the Golgi rings have increased both in numbers and size.

Lastly, we wish to emphasise the fact that in all eggs in which the Golgi apparatus is said to give rise to yolk (for reference see NATURE, May I5, I926), such yolk is always fatty. This in itself is confirmatory of the above view, because the Golgi material is supposed to be a lipoid combined with a proteid

A full account will be published later.

VISHWA NATH.

(Bhupindra Research Laboratory, Patiala.)

Tasdique Husain.

(Government College, Lahore.)

Central Research Institute,

Kasauli (India)

September 9 .

\section{Kammerer's Alytes.}

MAY I be permitted to reply briefly to Dr. Noble's letter on Kammerer's Alytes which appeared in NATURE of October 9 ? There are several questions involved: first, whether Dr. Noble was right in his statement to the British Association in 1925, that Kammerer's specimen did not show a genuine nuptial pad, because the characteristic glands were absent, and that the glands, not the spines, were diagnostic of these pads.

Champy, in his paper on the subject, states that the nuptial glands are merely the normal skin glands enlarged, and this is confirmed by Dr. Przibram's letter to NATURE of August 7.

Secondly, Dr. Noble makes the statement that the glands in Kammerer's controls shown in America were the same size as those in the sections of the pad.

This statement I can readily accept. I have photographs before me as I write both of Kammerer's earlier sections, sent to Bateson in 1919 , and of his later ones exhibited in Cambridge in I923. In the former the cornification of the epidermis is not so strongly developed as in the latter, and the disparity in size between the glands in the sections through pad and control is slight. In the latter, as stated, the glands in the pad are double the size of those in the control and the cornification is very strong. Kammerer obtained many of the modified males and reared them through several generations, and the acquired peculiarities became intensified in later generations.

'As to the date at which the Alytes specimen was ' faked,' there are two passages in Dr. Noble's description which completely give his case away. His letter suggests that Dr. Kammerer perpetrated a wicked fraud on the scientific world. Dr. Noble could find no spines on the specimen in Vienna, and saw blackened patches on both hands: I saw spines and have a photograph of them, and on one of the hands I saw no blackened patch whatever.

Dr. Noble's reference to the large-eyed Proteus shows that he fails to grasp its bearing on the question. I consider it the most wonderful object ever exhibited to a scientific audience. The larval Proteus does not, as Dr. Noble suggests, possess an eye: it has, like other blind cave-animals, only the embryonic rudiment of one. If Dr. Noble can find other 'casual' examples of blind cave-animals developing large eyes, I shall be glad to hear of them.

Both the Alytes and the Proteus specimens are examples of the same phenomenon-a phenomenon termed by Prof. Semon 'ecphory'; that is, the revival of ancestral features by the reinstating of the ancestral environment. This process required for its completion five or six generations in Alytes and in Proteus only one, but it is essentially the same thing in both; and to try to represent the skilled experimenter who produced the Proteus as a clumsy trickster seems to me to be both unjust and unworthy

I do not propose to discuss the merits of the inheritance of acquired characters in the present issue, but as Dr. Noble seems unconscious of the rising tide of Lamarckism, let me point out that Kammerer's conclusions are being confirmed by workers dealing with quite different animals, the last and most spectacular of these confirmations being the paper on the inheritance of habit by rats, read at the Oxford meeting of the British Association by Prof. William McDougall.

If Dr. Noble will forgive me for lapsing into his own expressive American, let me gently entreat him "to get on the band-waggon." Habit as the chief factor in evolution and the inheritability of acquired habits are accepted by leading systematists, palæontologists, and embryologists. Every year adds to the recruits, and I hope that Dr. Noble will join them. If he does, I am sure that he will "get the bulge" on many of his countrymen.

Royal College of Science,

E. W. MacBride,

South Kensington, S.W.7.

\section{The Anomalous Flocculation of Clay.}

Some further experiments have been performed in these laboratories which clear up the discrepancies between the experiments described in a previous letter on the above subject (NATURE, May r, p. 624) and those of Messrs. Kermack and Williamson (NATURE, June I2, p. 824).

The following table gives the times required to flocculate a $0 \cdot I$ per cent. purified clay suspension at various concentrations of sodium and calcium chlorides and hydroxides:

\begin{tabular}{|c|c|c|c|}
\hline \multirow{2}{*}{$\begin{array}{l}\text { Concn. } \\
\mathrm{Ca}^{\prime \prime} \text { ion. }\end{array}$} & \multicolumn{3}{|c|}{ Time required for flocculation. } \\
\hline & $\mathrm{Ca}(\mathrm{OH})_{2}$ & $\mathrm{CaCl}_{2}$. & $\begin{array}{l}\text { Two equivalents of } \\
\text { chlorides to one of } \\
\text { hydroxide. }\end{array}$ \\
\hline $0.00 \mathrm{I}$ & 7 hours & $14 \mathrm{~min}$. & 6 hours \\
\hline 0.002 & $28 \mathrm{~min}$. & Io , & $32 \mathrm{~min}$. \\
\hline 0.003 & $2 \quad$, & $7 \quad$, & I2 , \\
\hline $0.00_{4}$ & $1 \cdot 5 \quad$, & , & $4 \cdot 5$ \\
\hline 0.005 & I. $5 \quad$, & 6 & $3 \cdot 5$ \\
\hline 0.010 & $I \cdot 5 \quad$, & 6 & $I \cdot 5$ \\
\hline $\mathrm{o} \cdot \mathrm{OI}_{4}$ & $\mathrm{I} \cdot 5 \quad$, & $6 \quad$, & $\mathrm{I} \cdot 5 \quad$ I \\
\hline $\begin{array}{l}\text { Concn. } \\
\text { Na jon. }\end{array}$ & $\mathrm{NaOH}$. & $\mathrm{NaCl}$. & $\mathrm{NaCl}: \mathrm{NaOH}=2: \mathrm{I}$ \\
\hline 0.05 & 2 hours & I3 $\mathrm{min}$. & 2 hours \\
\hline $0 \cdot \mathbf{I}$ & $32 \mathrm{~min}$. & $r_{3} \quad$, & $32 \mathrm{~min}$. \\
\hline $0 \cdot 2$ & $22 \quad$, & I 4 , & $24 \quad$, \\
\hline 0.5 & $20 \quad$, & I7, , & $17 \quad$, \\
\hline $0 \cdot 9$ & I 5 , & I8 , & I4 ", \\
\hline
\end{tabular}

These results show that calcium hydroxide is a less powerful coagulant than calcium chloride, and actually tends to stabilise a suspension containing the latter salt, provided that the time of flocculation is longer than about twelve minutes.

If the concentration is such that coagulation takes place in 6 minutes or less, then calcium hydroxide flocculates more rapidly than the chloride at equivalent concentrations.

The results for sodium, on the other hand, suggest that even this latter effect should not be called anomalous, as at a concentration 0.9 normal, sodium 